\title{
Energy and Exergy Analysis of Ship Energy Systems - The Case study of a Chemical Tanker
}

\author{
Authors: F. Baldi*1 ${ }^{1}$, H. Johnson ${ }^{2}$, C. Gabrielii ${ }^{3}$, K. Andersson ${ }^{4}$ \\ Department of Shipping and Marine Technology, Chalmers University of Technology \\ Gothenburg, Sweden \\ E-mail: ${ }^{1}$ francesco.baldi@chalmers.se, ${ }^{2}$ hannes.johnson@ chalmers.se, ${ }^{3}$ cecilia.gabrielii@ chalmers.se, \\ ${ }^{4}$ karin.andersson@chalmers.se
}

Received 25 September 2014, Accepted 17 April 2015

\begin{abstract}
Shipping contributes today to $2.1 \%$ of global anthropogenic greenhouse gas emissions and its share is expected to grow together with global trade in the coming years. At the same time, bunker prices are increasing and companies start to feel the pressure of growing fuel bills in their balance sheet.

In order to address both challenges, it is important to improve the understanding of the energy consumption trends on ships through a detailed analysis of their energy systems. In this paper, energy and exergy analysis are applied to the energy system of a chemical tanker, for which both measurements and technic knowledge of ship systems were available. The application of energy analysis to the case-study vessel allowed for the comparison of different energy flows and therefore identifying system components and interactions critical for ship energy consumption. Exergy analysis allowed instead identifying main inefficiencies and evaluating waste flows.

Results showed that propulsion is the main contributor to ship energy consumption (70\%), but that also auxiliary heat $(16.5 \%)$ and power $(13.5 \%)$ needs are relevant sources of energy consumption. The potential for recovering waste heat is relevant, especially from the exhaust gases, as their exergetic value represents $18 \%$ of the engine power output.
\end{abstract}

\section{Keywords: Energy analysis; exergy analysis; shipping; energy efficiency.}

\section{Introduction}

As shipping is facing a number of challenges related to increased fuel costs and stronger focus on environmental impact energy efficiency is more and more a subject of study. In this condition, however, detailed studies on energy generation, use and losses on board, together with similar evaluations related to exergy, are lacking in existing scientific literature.

\subsection{Background}

International trade is the core of today's economy and lifestyle. Its size, compared to 1950, is today more than 100 times larger in terms of volume and value of goods transported [1]. In this picture shipping, which is responsible for between $80 \%$ and $90 \%$ of the overall global trade [2] has a crucial role in global economy and, more in general, in all human activities.

However, shipping is now subject to a large number of important challenges. Bunker fuel prices are today three times higher than they were in the 80's [3], and fuel costs are estimated to account for between $43 \%$ and $67 \%$ of total operating costs depending on vessel type [4]. Moreover, upcoming environmental regulations on sulfur oxides, nitrogen oxides and greenhouse gases (shipping is estimated to contribute to $2.1 \%$ of global anthropogenic GHG emissions [5]) will exert an additional leverage on fuel costs [6]. This phenomenon will be more pronounced in emission controlled areas, i.e. USA coastal waters, the
Baltic Sea, and the North Sea, where regulations will be stricter.

Various fuel saving solutions for shipping are available and currently implemented. Operational measures include improvements in voyage execution, engine monitoring, reduction of auxiliary power consumption, trim/draft optimization, weather routing, hull/propeller polishing, slow-steaming. Design related measures can relate to the use of more efficient engines and propellers, improved hull design, air cavity lubrication, wind propulsion, fuel cells for auxiliary power generation, waste heat recovery, liquefied natural gas as fuel, pump frequency converters, cold ironing [7]. Several scientific studies have been conducted on these technologies, and a more detailed investigation would be out of the scope of this work.

Even if efforts have been put in order to evaluate the benefits associated with the use of each of these solutions and of their combined effect [7], [8], it has also been acknowledged that the world fleet is heterogeneous; from the perspective of a ship owner or operator, measures need to be evaluated on a ship-to-ship basis [9]. In this process, a deeper understanding of energy use on board of the specific ship is vital.

\subsection{Previous Work}

Some studies presenting the analysis of ship energy systems can be found in literature. Thomas et al. [9] and Basurko et al. [10] worked on energy auditing fishing vessels; Shi et al. [11], [12] proposed models for predicting 
ship fuel consumption in design and off-design conditions; Balaji and Yaakob [13] analyzed ship heat availability for use in ballast water treatment technologies. However, a more thorough, holistic thermodynamic analysis of a ship, such as that proposed by Nguyen et al. [14] for oil platforms, is, to the best of our knowledge, lacking in scientific literature. The work proposed by Zaili and Zhaofeng [15], though looking in the right direction, still does not represent the required level of detail as they only focus on the main engines and propose an analysis based on design values rather than on measured data.

Analyses based on the First law of thermodynamics lack insight of the irreversibilities of the systems, as well as of the different quality of heat flows, since they do not account for the additional knowledge provided by the Second law of thermodynamics [16]. Exergy analysis, which is based on both the First and the Second laws of thermodynamics, can help addressing this shortcoming. Widely used in other industrial sectors, exergy analysis in not commonly employed in maritime technology studies, and is mostly related to waste heat recovery systems [17], [18] and refrigeration plants [19], [20].

\subsection{Aim}

The aim of this paper is to provide a better understanding of how energy is used on board of a case study vessel and where the largest potential for improvement is located by performing an energy and an exergy analysis of a the ship's energy systems. Compared to what can be found in the scientific literature, the present research presents elements of novelty, because it:

- Is based on a combination of measurements and design information.

- $\quad$ Embraces all ship energy systems.

- Analyses energy input, output, and internal energy

flows.

- $\quad$ Focuses on both energy and exergy analysis, hence including considerations about energy quality.

\section{Methodology}

The methodology employed in this work consists in the analysis of measured operational data with the aid of technical knowledge of the system and theoretical principles whenever measured data are not available or the quantity of interest is not directly measureable.

\subsection{Exergy Analysis}

When dealing with energy flows of different nature, energy analysis alone can lead to misleading results, as it does not account for energy quality. This problem can be partially overcome by the use of exergy analysis. Exergy is defined as the maximum shaft work that can be done by the a system in a specified reference environment [16]. The exergy content of a flow depends on the quality of the energy content. Additionally, differently from energy, exergy is not conserved and can be destroyed, representing the deterioration of energy quality.

The exergy content of a material flow is generally divided in four parts: physical, chemical, kinetic and potential. Potential and kinetic exergy flows coincide with their energy counterparts. In the case of chemical exergy, substantial differences can be found when analyzing systems involving a more advanced chemistry; in this case combustion is the only chemical reaction taken into account, and it is assumed that the specific chemical exergy content of the fuel can be calculated as suggested by [21] based on its LHV and its $\mathrm{H} / \mathrm{C}$ ratio. Finally, the physical component of an exergy flow is defined as showed in Eq. (1).

$\dot{B}_{p h}=\dot{m}\left[\left(h-h_{0}\right)+T_{0}\left(s-s_{0}\right)\right]$

where $\dot{B}, h$, and $s$ respectively stand for exergy flow, specific enthalpy, and specific entropy, while the subscript 0 refers to reference conditions, which in this work coincide with measurements of seawater temperature.

Energy flows that are not associated to material stream flows are also associated to a corresponding exergy flow. In the case of work and electricity the exergy exchanged coincides with the correspondent amount of energy; in the case of heat, the exergy exchanged depends on the temperature at which the exchange takes place, according to Eq. (2):

$\dot{B}_{\text {heat }}=\dot{Q}\left(1-\frac{T_{0}}{T}\right)$

With reference to an open system, the exergy balance of the system can be expressed in accordance with Eq. (3):

$\dot{B}_{\text {in }}=\dot{B}_{\text {out }}+\dot{I}$

where $\dot{B}_{\text {in }}$ and $\dot{B}_{\text {out }}$ represent the flow of exergy entering and leaving the component, respectively. The term $\mathrm{I}^{\cdot}$ is known as irreversibility rate (or exergy destruction) and can be calculated, in its general form, as:

$\dot{I}=T_{0} \dot{S}_{g e n}$

where $\dot{S}_{g e n}$ represents the entropy generation rate in the component.

Accounting for the second law of thermodynamics allows for a large number of possible definitions of efficiency, and there is limited agreement in the scientific community concerning what exergy-based efficiencies are to be used in these analyses. In this study, four different quantities measuring efficiency according to exergy analysis will be used based on the work of Kotas [16] and Lior and Zhang [22]:

- The total exergy efficiency $\left(\varepsilon_{t}\right)$ is used in this study as defined by [22] according to Eq. (5)

$\varepsilon_{t}=\frac{\sum \dot{B}_{o u t}}{\sum \dot{B}_{\text {in }}}$

where the subscripts out and in respectively refer to outputs and inputs. As suggested by Kotas [16] and originally proposed by Bruges [23], in the case of heat exchangers Eq. (5) can be interpreted as presented in Eq. (6) by assuming the reduction in exergy of the hot stream as the input to the system and the increase in exergy of the cold stream as the desired output: 


$$
\varepsilon_{t}=\frac{\dot{B}_{c, \text { out }}-\dot{B}_{c, \text { in }}}{\dot{B}_{h, \text { out }}-\dot{B}_{h, \text { in }}}
$$

- The task efficiency $\left(\varepsilon_{u}\right)$ is used in this study as defined by Lior and Zhang [22] according to Eq. (7).

$$
\varepsilon_{u}=\frac{\sum \dot{W}_{u}-\sum \dot{W}_{p}+\sum \dot{B}_{h, u}+\sum \dot{B}_{c, u}}{\sum \dot{B}_{h, p}+\sum \dot{B}_{c, p}+\sum \dot{B}_{c h, p}}
$$

where the subscripts $u, p, h$ and $c$ represent the "useful" output of the system, the "paid" input to the system, heating and cooling flows. In this study, the equation originally proposed by Lior and Zhang [22] was adapted by also including fuel exergy inputs to the denominator of the fraction. The task efficiency is not used for heat exchangers, in this study, as depending on whether it is applied to a heater or a cooler the result would be $\varepsilon_{u}=\varepsilon_{t}$ or $\varepsilon_{u}=\varepsilon_{t}^{-1}$, none of which would add significant contribution to the analysis.

- The efficiency loss ratio $(\delta)$ is used according to the definition proposed by Kotas [24] and represents the proportion of the exergy input to a component that is lost due to irreversibilities:

$$
\delta=\frac{\dot{I}}{\sum \dot{B}_{i n}}
$$

In the case of heat exchangers, the difference $\dot{B}_{h, \text { out }}-\dot{B}_{h, \text { in }}$ is used as denominator to the equation instead in order to be consistent with the definition of total exergy efficiency.

- The relative irreversibility $(\gamma)$ is defined as the ratio between the exergy destroyed in the component "i" and the total rate of exergy destruction in the whole system:

$$
\gamma=\frac{\dot{I}_{i}}{\sum \dot{I}_{i}}
$$

\subsection{Ship Description}

The ship under study is a Panamax chemical / product tanker. Relevant ship features are provided in Table 1, while Figure 1 conceptually represents the ship energy systems. Figure 2 gives a more detailed representation of the main engine systems, including the cooling systems. The ship is propelled by two 4-stroke Diesel engines (ME) rated 3,840 kW each. The two engine shafts are connected to a common gearbox (GB). One of the gears reduces the rotational speed from $600 \mathrm{rpm}$ to $105.7 \mathrm{rpm}$, the design speed for the controllable pitch propeller.

Another shaft from the gearbox connects it to the electric generator (SG) which provides $60 \mathrm{~Hz}$ current to the ship. Additionally, two auxiliary engines (AE) rated 682 $\mathrm{kW}$ each can provide electric power when the MEs are not in operation, or whenever there is a failure in the SG.
Auxiliary heat needs are fulfilled by the exhaust gas economizers (EGE) or by auxiliary boilers (AB) when the MEs are not running or heat demand is higher than what provided by the EGEs.

Table 1. Main Ship Features.

\begin{tabular}{ll}
\hline Dimension & Value \\
\hline Deadweight & $47,000 \mathrm{tons}$ \\
Installed power (Main Engines) & $7,700 \mathrm{~kW}$ \\
Installed power (Auxiliary Engines) & $1,400 \mathrm{~kW}$ \\
Shaft generator design power & $3,200 \mathrm{~kW}$ \\
Exhaust boilers design steam gen. & $1,400 \mathrm{~kg} / \mathrm{h}$ \\
Auxiliary boilers design steam gen. & $28,000 \mathrm{~kg} / \mathrm{h}$ \\
\hline
\end{tabular}

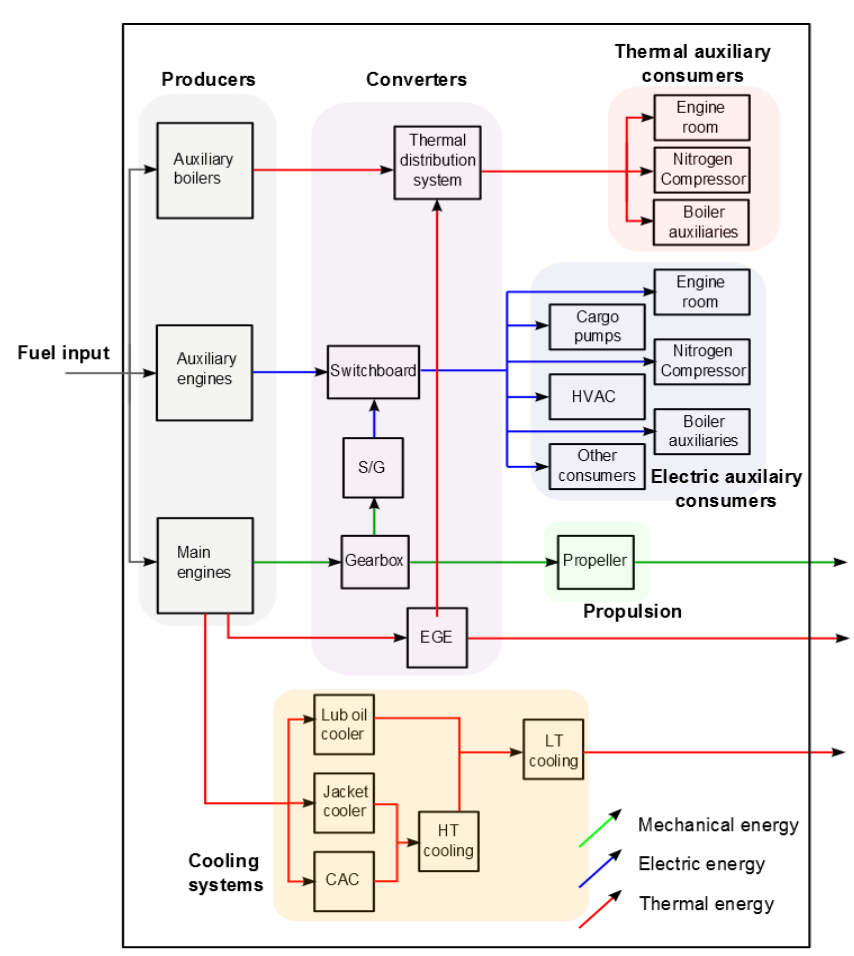

Figure 1. Conceptual representation of ship energy systems.

\subsection{Data Gathering and Processing}

The main source of measured data for the analysis is a continuous monitoring system (CMS) installed on board. Measurements are logged on board with a frequency of 1 to $15 \mathrm{~s}$ depending on the measured quantity. The raw data are sent to the energy management system provider, where they are elaborated and made available online to the company as $15 \mathrm{~min}$ averages. The $15 \mathrm{~min}$ averaged dataset was used for the analysis in this work.

These data were filtered in order to eliminate entries that showed to be clearly inconsistent (e.g. negative fuel flows). Unfortunately, as a consequence of not having access to the raw measurements, it was not possible to derive information in relation to measurement accuracy in addition to what provided by the shipyard $( \pm 0.1 \%$ for propeller speed, $\pm 2 \%$ for propeller power, $\pm 3 \%$ for main engines fuel flow). The analysis was therefore performed under the assumption that no relevant bias was present in the original data as a consequence of measurement inaccuracies. 


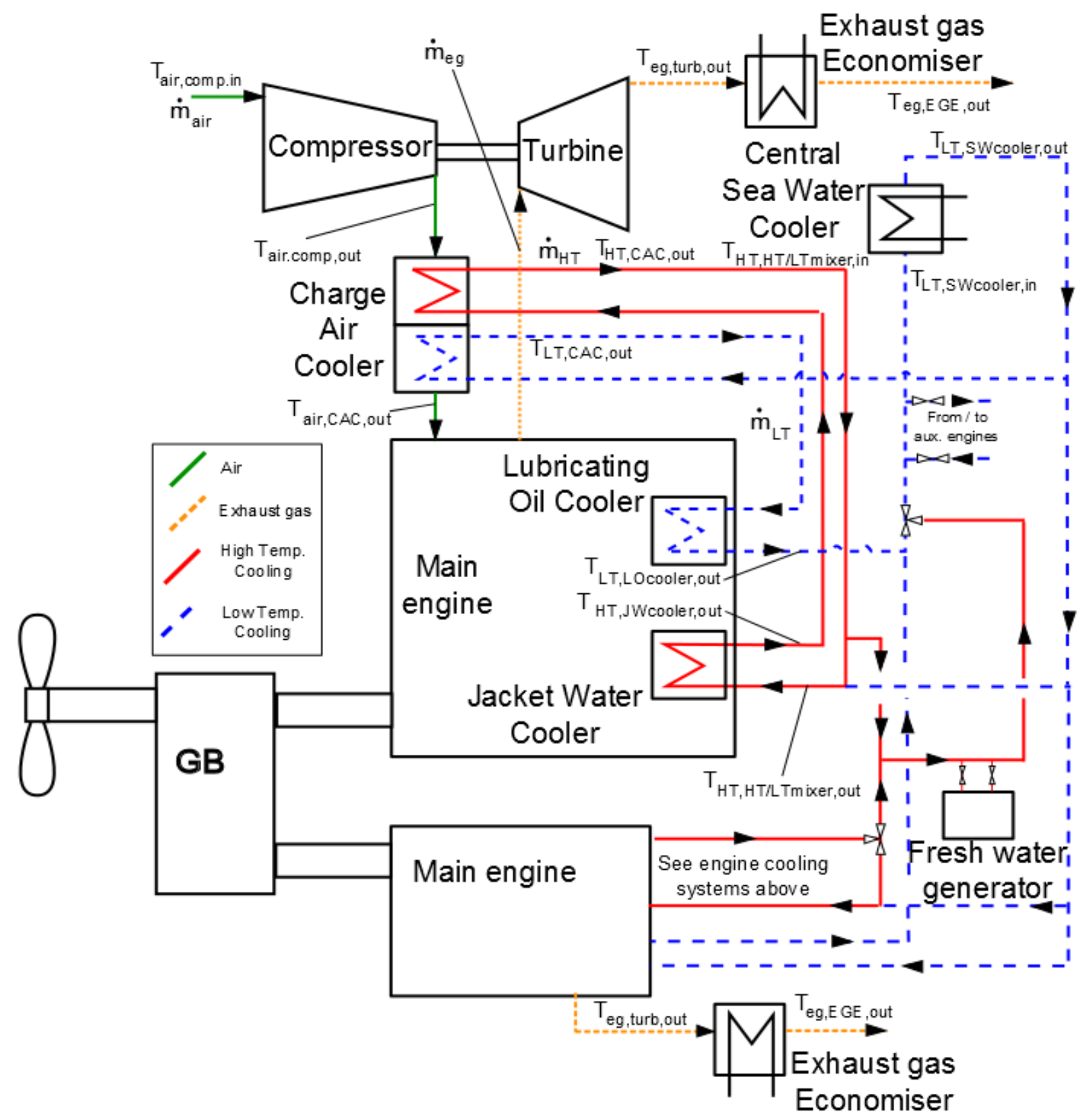

Figure 2. Conceptual representation of main engine systems.

Values available from the CMS were:

- Propeller torque

- Propeller speed

- Propeller power

- Engine fuel consumption

- Auxiliary generator power output

- Auxiliary engines fuel consumption

- Main engines fuel consumption

- Shaft generator power output

- Ship speed

- Sea water temperature

- Ambient temperature

- Ambient pressure

In addition to the aforementioned approximations, it should be noted the measurements in moments of highly dynamic behavior (i.e. maneuvering) were filtered out from the averaged dataset. This was done as a consequence of clear inconsistence in the calculated engine efficiency, which is apparently generated by the averaging process.
The amount of data points filtered out of the database sum up to a negligible amount of the total $(0.8 \%)$ and does therefore not influence the reliability of the final results.

In addition to logged measurements, technical documentation was available for on board machinery and was used as input for numerical regressions: heat and electric balance of the ship were provided by the shipyard; ship sea trials performed by the shipyard when the ship was first sailed and direct communication with on board and onshore personnel were also available.

Engine properties are based on measurements of power, speed and fuel mass flow and on empirical polynomial regressions based on information provided by the engine manufacturer. A detailed accounting of all relationships and assumptions employed in this study in order to process the raw measured data are shown in Tables A1 to A3 in Appendix A. Table 2 shows the values taken by the main engine parameters given specific measured inputs of power and fuel flow rate; exergy flows from the engine are similarly shown in Figure 3. 
Table 2: Calculated Engine Temperatures and Flows for Different Total Main Engines Power. Values Marked with* Are Calculated in the Table, But Measured in the Application of the Model to the Case Study.

\begin{tabular}{|c|c|c|c|c|c|c|c|}
\hline Power $[\mathrm{kW}]$ & 1500 & 2500 & 3500 & 4500 & 5500 & 6500 & 7500 \\
\hline \# Engines running & 1 & 1 & 2 & 2 & 2 & 2 & 2 \\
\hline Engine load & 0.39 & 0.65 & 0.46 & 0.59 & 0.72 & 0.85 & 0.98 \\
\hline Engine bsfc $[\mathrm{g} / \mathrm{kWh}]$ & $224^{*}$ & $206^{*}$ & $218^{*}$ & $209 *$ & $204^{*}$ & $203^{*}$ & $207^{*}$ \\
\hline$\dot{m}_{\text {air }}\left[\frac{k g}{s}\right]$ & $2.8^{*}$ & $4.6^{*}$ & $6.5^{*}$ & $8.3^{*}$ & $10.2^{*}$ & $12.1^{*}$ & $13.9 *$ \\
\hline$T_{\text {air }, \text { Comp,in }}[K]$ & 308 & 308 & 308 & 308 & 308 & 308 & 308 \\
\hline$T_{\text {air,Comp }, \text { out }}[K]$ & 376 & 441 & 397 & 429 & 452 & 473 & 494 \\
\hline$T_{\text {air }, C A C, \text { out }}[K]$ & 328 & 328 & 328 & 328 & 328 & 328 & 328 \\
\hline$\dot{m}_{e g}\left[\frac{k g}{s}\right]$ & 2.9 & 4.8 & 6.7 & 8.6 & 10.5 & 12.4 & 14.3 \\
\hline$T_{\mathrm{eg}, \text { Turb }, \text { in }}[K]$ & 749 & 736 & 745 & 738 & 737 & 747 & 770 \\
\hline$T_{\text {eg,Turb,out }}[K]$ & 687 & 614 & 664 & 627 & 605 & 595 & 600 \\
\hline$T_{\text {eg, } E G E, \text { out }}[K]$ & 573 & 546 & 615 & 590 & 574 & 569 & 577 \\
\hline$T_{L O, \text { LOcooler }, \text { in }}[K]$ & 337 & 337 & 337 & 337 & 337 & 337 & 337 \\
\hline$T_{L O, \text { LOcooler,out }}[K]$ & 352 & 355 & 353 & 354 & 356 & 358 & 361 \\
\hline$T_{\mathrm{HT}, J \text { Jcooler,in }}[K]$ & 351 & 345 & 350 & 347 & 343 & 340 & 335 \\
\hline$T_{\mathrm{HT}, J \text { Jcooler,out }}[K]$ & 356 & 351 & 355 & 353 & 350 & 347 & 344 \\
\hline$T_{\mathrm{HT}, C A C, \text { out }}[K]$ & 358 & 358 & 358 & 358 & 358 & 358 & 358 \\
\hline
\end{tabular}

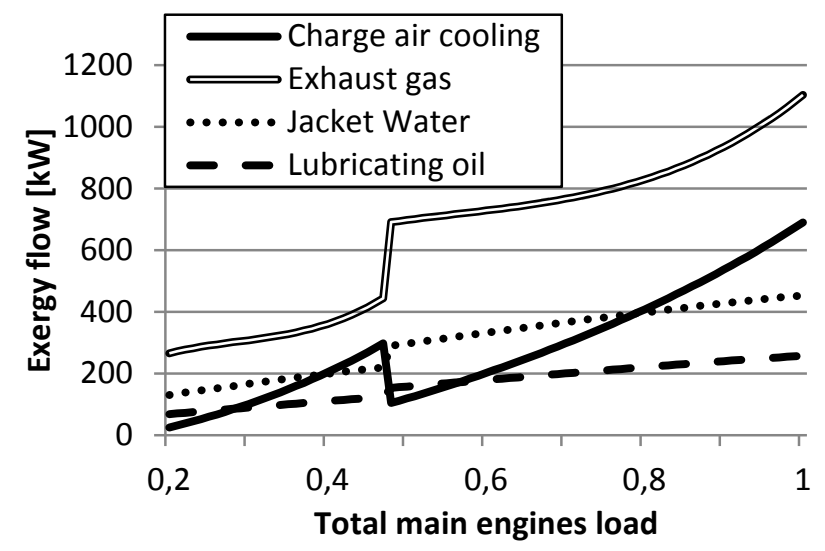

Figure 3: Calculated exergy flows for different values of total main engines power.

Auxiliary power consumption measurements are available from the CMS. These measurements, however, do not include details about the individual consumers. In order to give an estimation of the power needed by different consumers, information from the electric balance was used. Since the measured consumption is different from design figures, this operation required a number of assumptions:

- For seagoing mode (loaded), it is assumed that the power consumption is subdivided according to the electric balance. Therefore, proportions between different consumers are maintained. For all points where auxiliary load is larger than $500 \mathrm{~kW}$ nitrogen compressors are assumed to account for the additional consumption. Nitrogen compressors are needed for keeping an inert atmosphere into the cargo tanks when inflammable liquids are transported.

- For seagoing mode (ballast) the same repartition is assumed as for seagoing mode (loaded) if auxiliary power is lower than $500 \mathrm{~kW}$. If power consumption is higher the difference is assumed to be connected to the operations of nitrogen compressors and boilers auxiliaries (in connection to tank cleaning), which are subdivided according to their respective design power.

- For maneuvering the same assumptions as for seagoing mode (loaded) are employed.

- For cargo loading and unloading all consumption going over $500 \mathrm{~kW}$ is allocated to nitrogen compressors and cargo pumps, with repartition according to maximum installed power. It should be noted that cargo loading operations normally do not require the use of cargo pumps, as port storage facilities can provide the needed overpressure for loading the cargo.

- For waiting time the same proportions as reported in the ship electric balance are used, with the exception of engine room consumption, which is halved, since when waiting in port only auxiliary engines are used.

Fuel heating is needed because of high fuel viscosity, and is computed starting from the design heat balance and using sea water temperature and outer air temperature measurements. Hotel facilities needs are calculated assuming a linear correlation between calculated values given in the heat balance, assumed at an outer temperature of $2{ }^{\circ} \mathrm{C}$, depending on outer air temperature. Heat consumption for fresh water generation is calculated including service water for machinery and cooling systems and consumption for the crew according to common practice [25]. Since the generation of fresh water is connected to the (HT) cooling systems, the value of heat of vaporization for water was taken at $50^{\circ} \mathrm{C}$ and equal to 2382 $\mathrm{kJ} / \mathrm{kg}$.

During ballast legs, saturated steam at 14 bar is needed for tank cleaning, which requires the operation of the auxiliary boilers. Energy use for tank cleaning is derived from the aggregated boiler fuel consumption, under the 
assumption of $90 \%$ boiler efficiency accounting for combustion losses and heat flow in the exhaust gas, limited at $200^{\circ} \mathrm{C}$ to prevent sulfuric acid condensation in the funnel. Auxiliary boilers are also used when the main engines are not in operation. In this condition, as boilers are operated at very low load, a reduced efficiency of $80 \%$ was assumed instead.

\section{Results}

\subsection{Energy Analysis}

Figure 4 shows the Sankey diagram of ship energy systems. Summaries of cumulated input and output energy flows over one year of ship operations are shown in Tables 3 and 4, while Table 5 presents an overview of all the ship flows analyzed in this study.

Propulsion represents the main source of energy consumption, as it accounts for $68 \%$ of the yearly ship energy demand. This also translates in the main engines consuming the largest share of the overall energy input of the system (87.9\%). Hence, efforts directed towards the reduction of propulsive power are highly justified for the ship under study.

Both auxiliary engines and auxiliary boilers (respectively representing $8.0 \%$ and $4.1 \%$ of ship energy input) on one side, and auxiliary power and heat consumers (12\% and $20 \%$ of ship energy demand respectively) on the other, should be given significant attention.

Boiler auxiliary electric demand should also be taken into account as it also represents a significant share of the total demand $(2.7 \%)$.
Table 3: Summary of Input Energy Flows.

\begin{tabular}{lrrr}
\hline Input flow & Flow type & $\dot{E}\left[\frac{T J}{y e a r}\right]$ & $\dot{E}\left[\%_{\text {in,tot }}\right]$ \\
\hline Fuel to MEs & Chemical & 187.6 & $87.9 \%$ \\
Fuel to AEs & Chemical & 17.0 & $8.0 \%$ \\
Fuel to boilers & Chemical & 8.7 & $4.1 \%$ \\
\hline
\end{tabular}

Table 4: Summary of Output Energy Flows.

\begin{tabular}{lcrr}
\hline \multicolumn{1}{c}{ Output flow } & Flow type & $\dot{E}\left[\frac{T J}{\text { year }}\right]$ & $\dot{E}\left[\%_{\text {out,tot }}\right]$ \\
\hline Propulsion & Work & 67.7 & $31.7 \%$ \\
Tank cleaning & Heat & 3.1 & $1.5 \%$ \\
Fuel heating & Heat & 7.7 & $3.6 \%$ \\
Hotel facilities & Heat & 9.6 & $5.4 \%$ \\
Nitrogen & Electricity & 2.1 & $1.0 \%$ \\
compressors & Electricity & 0.8 & $0.4 \%$ \\
Cargo pumps & Electricity & 1.8 & $0.8 \%$ \\
HVAC & Electricity & 1.5 & $0.7 \%$ \\
Engine room & 2.7 & $1.3 \%$ \\
Boiler auxiliaries & Electricity & 2.6 & $1.2 \%$ \\
Miscellaneous & Electricity & 45.9 & $21.5 \%$ \\
Exhaust gas (ME) & Waste heat & 4.4 & $2.1 \%$ \\
Exhaust gas (AE) & Waste heat & 1.4 & $0.7 \%$ \\
Exhaust gas (AB) & Waste heat & 6.2 & $2.9 \%$ \\
Radiated heat & Waste heat & 52.1 & $24.4 \%$ \\
(ME) & Waste heat & 0.7 & $0.3 \%$ \\
Sea water cooling & Waste heat & 1.0 & $0.5 \%$ \\
Shaft losses & Waste heat & \\
SG losses & &
\end{tabular}

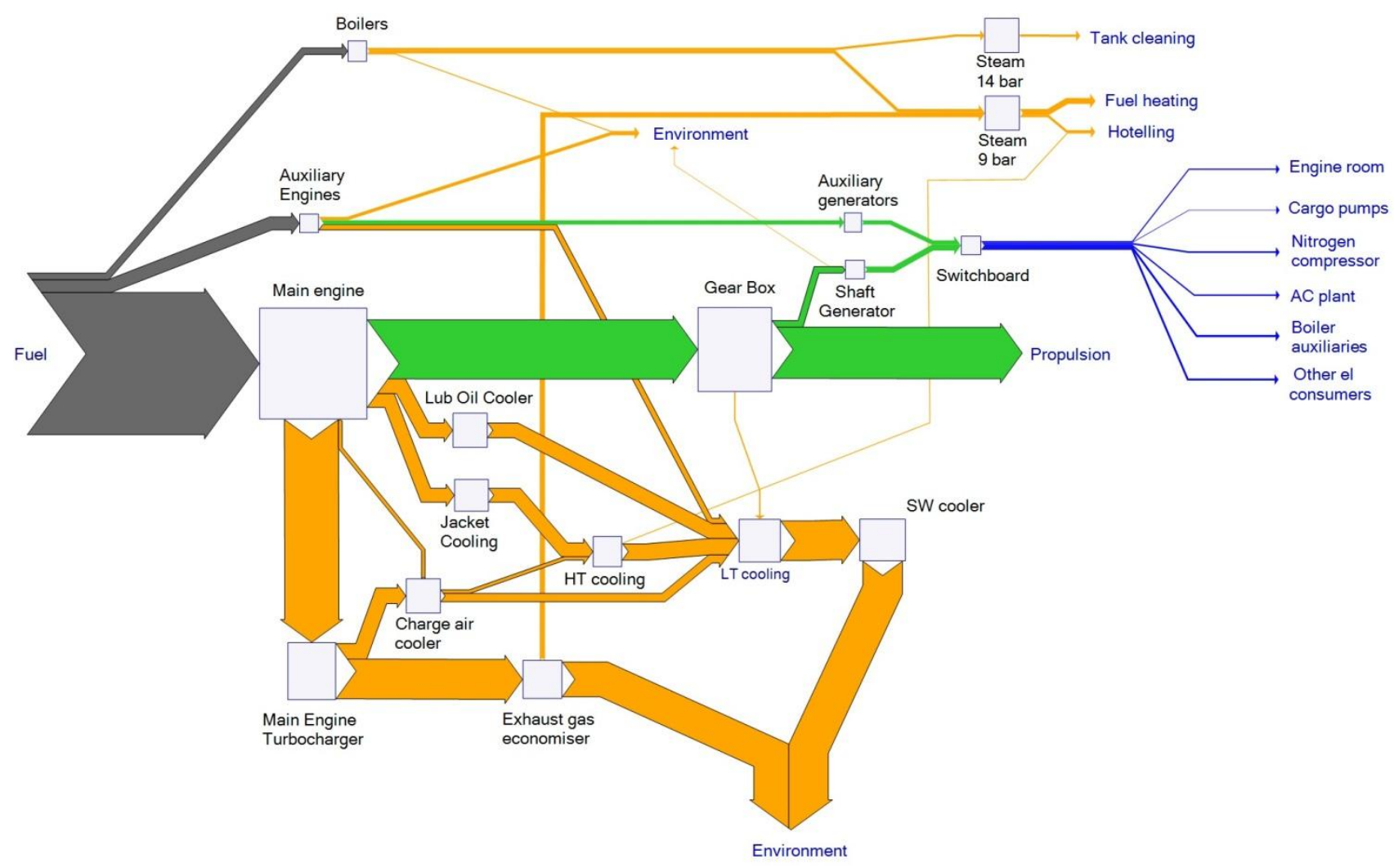

Figure 4. Sankey diagram of ship energy systems. 
Table 5: Yearly Energy Flows for the Selected Case Study Vessel, in TJ/year.

\begin{tabular}{|c|c|c|c|c|c|c|c|c|c|}
\hline cComponent & $\dot{E}_{c h, i n}$ & $\dot{E}_{p h, c, i n}$ & $\dot{E}_{p h, c, \text { out }}$ & $\dot{E}_{p h, h, i n}$ & $\dot{E}_{p h, h, \text { out }}$ & $\dot{E}_{w, i n}$ & $\dot{E}_{w, \text { out }}$ & $\dot{E}_{q, i n}$ & $\dot{E}_{q, \text { out }}$ \\
\hline Cylinders (ME) & 187.6 & 5.5 & 71.3 & 0.0 & 0.0 & 0.0 & 78.0 & 0.0 & 43.9 \\
\hline Turbocharger (ME) & 0.0 & 1.8 & 20.4 & 71.3 & 52.6 & 0.0 & 0.0 & 0.0 & 0.0 \\
\hline Lub oil cooler (ME) & 0.0 & 44.8 & 64.3 & 61.7 & 42.3 & 0.0 & 0.0 & 0.0 & 0.0 \\
\hline Jacket water cooler (ME) & 0.0 & 148.0 & 166.2 & 0.0 & 0.0 & 0.0 & 0.0 & 18.1 & 0.0 \\
\hline CAC, HT stage (ME) & 0.0 & 166.2 & 170.9 & 20.4 & 15.7 & 0.0 & 0.0 & 0.0 & 0.0 \\
\hline CAC, LT stage (ME) & 0.0 & 33.8 & 44.8 & 15.7 & 4.7 & 0.0 & 0.0 & 0.0 & 0.0 \\
\hline LT/HT mixer & 0.0 & 64.3 & 85.9 & 169.7 & 148.0 & 0.0 & 0.0 & 0.0 & 0.0 \\
\hline SW cooler & 0.0 & 0.0 & 52.1 & 85.9 & 33.8 & 0.0 & 0.0 & 0.0 & 0.0 \\
\hline Exhaust Gas Economizer & 0.0 & 2.5 & 9.3 & 52.6 & 45.9 & 0.0 & 0.0 & 0.0 & 0.0 \\
\hline Gearbox & 0.0 & 0.0 & 0.0 & 0.0 & 0.0 & 78.0 & 76.2 & 0.0 & 1.8 \\
\hline Shaft generator & 0.0 & 0.0 & 0.0 & 0.0 & 0.0 & 8.6 & 7.8 & 0.0 & 0.8 \\
\hline Switchboard & 0.0 & 0.0 & 0.0 & 0.0 & 0.0 & 13.5 & 13.4 & 0.0 & 0.1 \\
\hline Boiler & 8.7 & 2.9 & 10.2 & 0.0 & 1.4 & 0.0 & 0.0 & 0.0 & 0.0 \\
\hline Tank cleaning & 0.0 & 0.0 & 0.0 & 4.5 & 1.3 & 0.0 & 0.0 & 0.0 & 3.1 \\
\hline Fuel heating & 0.0 & 0.0 & 0.0 & 10.6 & 2.8 & 0.0 & 0.0 & 0.0 & 7.7 \\
\hline Hotel facilities & 0.0 & 0.0 & 0.0 & 4.4 & 1.2 & 0.0 & 0.0 & 6.4 & 9.6 \\
\hline Auxiliary engines & 17.0 & 0.0 & 4.4 & 0.0 & 0.0 & 0.0 & 5.7 & 0.0 & 7.0 \\
\hline
\end{tabular}

Auxiliary boilers are run at low load most of the time, leading to low efficiency. Fuel heating also represents a surprisingly high share of the overall ship energy consumption $(7.8 \%)$. This high influence of auxiliary needs is partly connected to the ship spending large amount of time in port, when there is no propulsion power demand.

Finally, a large amount of energy is wasted to the environment through the exhaust gas $(21.5 \%$ of total ship energy output), and the SW cooler (24.4\%). This suggests that there is potential for the recovery of these waste flows. The amount of energy available in the cooling systems can however be evaluated more consistently using exergy analysis so to also account for the different energy quality of the available cooling flows.

\subsection{Exergy Analysis}

The results from the exergy analysis are presented graphically in Figure 5; a summary of exergy based efficiencies is presented in Table 6; Tables 7 and 8 present input and output exergy flows; Table 9 finally shows the detail of the exergy flows between components onboard.

The analysis of exergy flows shows a different picture from the energy analysis. Heat demand accounts for only $3.0 \%$ of the total onboard exergy demand, while propulsion $(83 \%)$ and auxiliary power (14\%) represent a higher relative share of the total demand.

Looking at waste flows, the results suggest that the main engine exhaust are by large the main source of exergy loss onboard (14.1\% of total ship exergy output). Exergy losses from sea water cooling are negligible.

Exergy efficiency helps understanding which components make the best use of the quality of their energy input. It can be seen, for example, that according to this definition, boilers $\left(\varepsilon_{\mathrm{t}}=36.3 \%\right)$ are much less efficient than both main $\left(\varepsilon_{\mathrm{t}}=59.2 \%\right)$ and auxiliary engines $\left(\varepsilon_{\mathrm{t}}=53.0 \%\right)$. This holds true when looking at task efficiency $\left(\varepsilon_{\mathrm{u}}\right)$, although the difference is smaller.

A further analysis of the cooling systems allows the identification of where the largest amount of exergy is destroyed. All the different coolers present a significant contribution of onboard exergy destruction, which sums up to $10.1 \%$ of the total. These irreversibilities could potentially be reduced thus providing an additional source of heat for energy recovery. When calculated at the engine output, the total amount of exergy available for recovery accounts for $10 \mathrm{TJ} / \mathrm{year}$, which is comparable to the amount available from the exhaust gas (13.8 TJ/year).

These results suggest that three is a significant potential for improving the efficiency of the energy system by enhancing the recovery of waste heat. Waste heat recovery (WHR) systems for heat-to-power conversion are often proposed for enhancing marine propulsion systems efficiency [18], [26]-[28] . In this context exergy analysis, compared to energy analysis, provides a more accurate estimate of the amount of power that could be generated through a WHR system.

The analysis of the total exergy efficiency $\left(\varepsilon_{t}\right)$ allows identifying where the aforementioned potential for improvement is larger. The LT stage of the CAC $\left(\varepsilon_{t}\right.$ $=25.5 \%$ ) appears to be the one where the highest potential for improvement is located, followed by the HT/LT mixer $(49 \%)$. Other coolers have efficiencies included between $52 \%$ and $55.5 \%$ (see Table 6).

In practice, however, these improvements would require larger heat exchangers, at the cost of an increased capital investment. This work focuses on a thermodynamic analysis of ship energy systems; methods for thermoeconomic analysis and optimization have been proposed in literature and should be employed in further developments of this work (e.g. by Szargut and Sama [29]).

The relatively high total exergyu efficiency of the EGE (67\%) was somewhat unexpected, since it generates relatively low pressure steam (9 bar, $448 \mathrm{~K}$ saturation temperature) at the expense of heat at higher temperatrure in the exhaust gas (between 650 and $550 \mathrm{~K}$, see Table 2). It should be noted, however, that among all the heat exchanger analysed in this work, the EGE is the only one that has a heating (rather than cooling) function. This suggests that it should not be directly compared with other exchangers meant for different purposes.

Heat demands for tank cleaning and fuel heating also involve a high rate of exergy destruction. In the first case, 14 bar steam generated by the auxiliary boilers is used to warm up water from 50 to $85^{\circ} \mathrm{C}$, which represents a clearly inefficient exchange; in the same way, the use of 9 bar steam for fuel heating, which mostly happen at temperatures comprised between 50 and $90^{\circ} \mathrm{C}$, is clearly identified by the exergy analysis as a potential source for improvement. In the case of hotel facilities, the use of HT water for freshwater generation increases the overall efficiency significantly. This could be done, for example, 
by using a different heat transfer fluid or, in alternative, steam at a lower pressure. Fuel handling and hoteling, for instance, only require temperatures as low as $70-80^{\circ} \mathrm{C}$ (a part from fuel heaters before the engine, which warm $\mathrm{HFO}$ up to around $90-100^{\circ} \mathrm{C}$ ), which could be provided at much lower temperature than by 9 bar steam.

Table 6: Exergy-based Efficiencies of Different Ship Components (\%).

\begin{tabular}{llllr}
\hline Component & $\varepsilon_{t}$ & $\varepsilon_{u}$ & \multicolumn{1}{l}{$\delta$} & \multicolumn{1}{l}{$\gamma$} \\
\hline Cylinders (ME) & 59.2 & 41.5 & 40.8 & 65.8 \\
Turbocharger (ME) & 35.6 & - & 64.4 & 5.8 \\
Lub oil cooler (ME) & 52.0 & - & 48.0 & 1.2 \\
Jacket water cooler (ME) & 53.7 & - & 46.3 & 2.2 \\
CAC, HT stage (ME) & 55.5 & - & 44.5 & 0.6 \\
CAC, LT stage (ME) & 25.5 & - & 74.5 & 1.3 \\
LT/HT mixer & 49.0 & - & 51.0 & 1.9 \\
SW cooler & 2.5 & - & 97.5 & 3.5 \\
Exhaust Gas Economizer & 67.0 & - & 33.0 & 1.0 \\
Gearbox & 98.3 & 97.7 & 1.7 & 1.1 \\
Shaft generator & 93.2 & 90.7 & 6.8 & 0.5 \\
Switchboard & 99.3 & 99.0 & 0.7 & 0.1 \\
Boiler & 36.3 & 28.0 & 63.7 & 5.1 \\
Tank cleaning & 25.3 & - & 74.7 & 0.7 \\
Fuel heating & 26.2 & - & 73.8 & 1.7 \\
Hotel facilities & 51.1 & - & 48.9 & 0.7 \\
Auxiliary engines & 53.0 & 33.5 & 47.0 & 6.9 \\
\hline
\end{tabular}

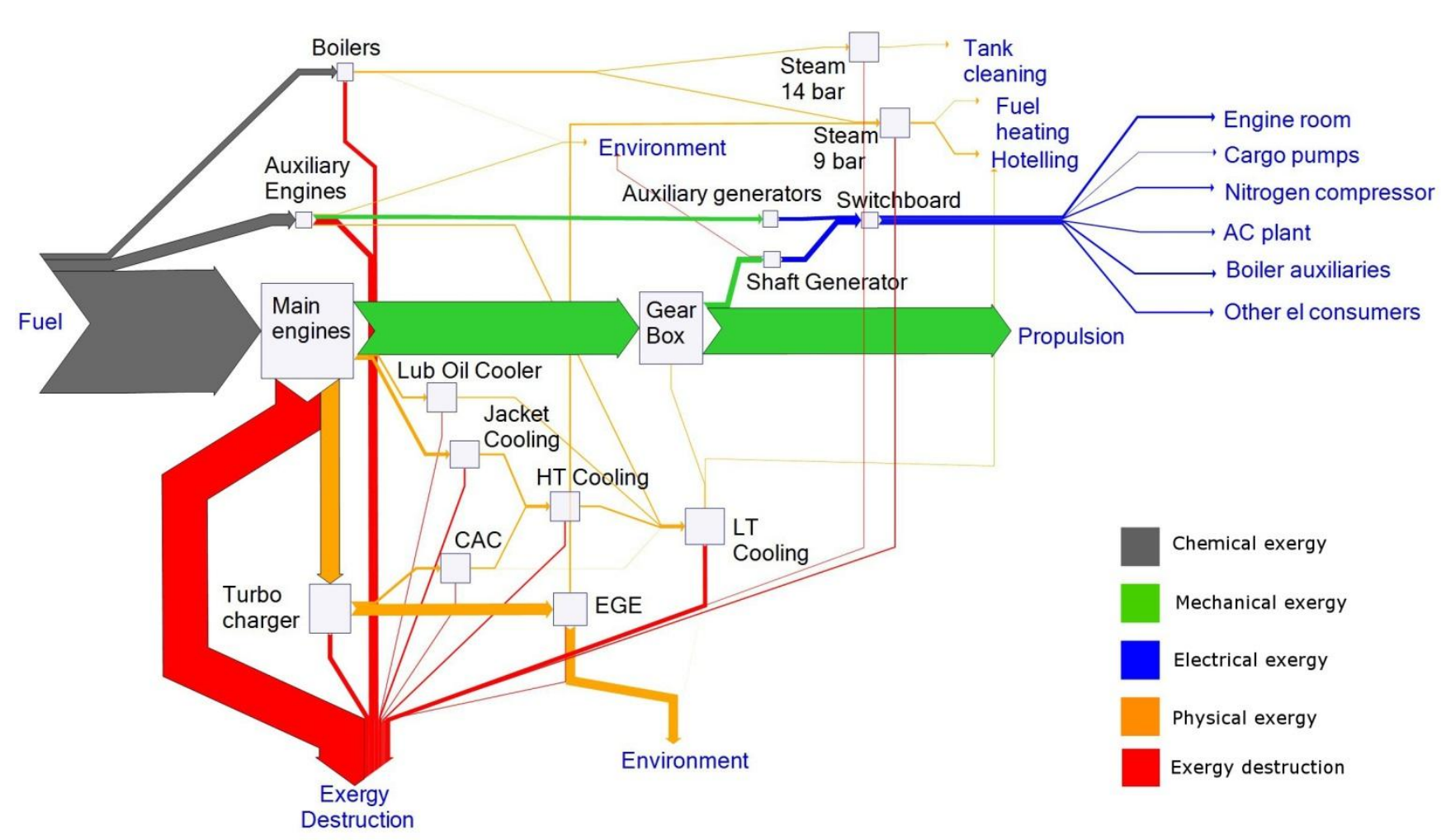

Figure 5. Grassmann diagram of ship energy systems.
Table 7: Summary of Input Exergy Flows.

\begin{tabular}{lrrr}
\hline & & $\dot{B}\left[\frac{T J}{y e a r}\right]$ & $\dot{B}\left[\%_{\text {in,tot }}\right]$ \\
& Flow type & \\
\hline Fuel to MEs & Chemical & 199.6 & 87.9 \\
Fuel to AEs & Chemical & 18.1 & 8.0 \\
Fuel to Boilers & Chemical & 9.3 & 4.1 \\
\hline
\end{tabular}

Table 8: Summary of Output Exergy Flows.

\begin{tabular}{llrr}
\multicolumn{1}{c}{ Output flow } & Flow type & $\dot{B}\left[\frac{T J}{\text { year }}\right]$ & $\dot{B}\left[\%_{\text {in,tot }}\right]$ \\
\hline Propulsion & Work & 67.6 & 69.0 \\
Tank cleaning & Heat & 0.9 & 0.9 \\
Fuel heating & Heat & 0.7 & 0.7 \\
Hotel facilities & Heat & 0.9 & 0.9
\end{tabular}

Nitrogen

compressors

Electricity

2.1

2.1

Cargo pumps

HVAC

Engine room

Electricity

Electricity

Electricity

$\begin{array}{ll}0.8 & 0.8\end{array}$

Boiler auxiliaries

Miscellaneous

Electricity

1.8

1.5

Electricity

2.7

1.8

Exhaust gas (AE)

Waste heat

2.6

13.8

1.9

0.2

0.0

Radiated heat

(ME)

Sea water cooling

Shaft losses

SG losses

0.1

0.2

0.2

Waste heat

Waste heat
Exhaust gas (ME) 
Table 9: Yearly Exergy Flows for the Selected Case Study Vessel, in TJ/year.

\begin{tabular}{|c|c|c|c|c|c|c|c|c|c|c|}
\hline Component & $\dot{B}_{c h, i n}$ & $\dot{B}_{p h, c, i n}$ & $\dot{B}_{p h, c, \text { out }}$ & $\dot{B}_{p h, h, i n}$ & $\dot{B}_{p h, h, \text { out }}$ & $\dot{B}_{w, i n}$ & $\dot{B}_{w, \text { out }}$ & $\dot{B}_{q, i n}$ & $\dot{B}_{q, \text { out }}$ & $\overline{\dot{I}}$ \\
\hline Cylinders (ME) & 199.6 & 0.4 & 27.8 & 0.0 & 0.0 & 0.0 & 78.0 & 0.0 & 5.5 & 76.7 \\
\hline Turbocharger (ME) & 0.0 & 0.0 & 3.8 & 27.8 & 17.3 & 0.0 & 0.0 & 0.0 & 0.0 & 6.8 \\
\hline Lubricating oil cooler (ME) & 0.0 & 1.4 & 2.9 & 5.7 & 2.8 & 0.0 & 0.0 & 0.0 & 0.0 & 1.4 \\
\hline Jacket water cooler (ME) & 0.0 & 12.3 & 15.3 & 0.0 & 0.0 & 0.0 & 0.0 & 5.5 & 0.0 & 2.5 \\
\hline CAC, HT stage (ME) & 0.0 & 15.3 & 16.1 & 3.8 & 2.3 & 0.0 & 0.0 & 0.0 & 0.0 & 0.6 \\
\hline CAC, LT stage (ME) & 0.0 & 0.9 & 1.4 & 2.3 & 0.3 & 0.0 & 0.0 & 0.0 & 0.0 & 1.6 \\
\hline LT/HT mixer & 0.0 & 2.9 & 5.0 & 16.7 & 12.3 & 0.0 & 0.0 & 0.0 & 0.0 & 2.2 \\
\hline SW cooler & 0.0 & 0.0 & 0.1 & 5.0 & 0.9 & 0.0 & 0.0 & 0.0 & 0.0 & 4.0 \\
\hline Exhaust Gas Economizer & 0.0 & 0.4 & 2.8 & 17.3 & 13.8 & 0.0 & 0.0 & 0.0 & 0.0 & 1.2 \\
\hline Gearbox & 0.0 & 0.0 & 0.0 & 0.0 & 0.0 & 78.0 & 76.2 & 0.0 & 0.5 & 1.3 \\
\hline Shaft generator & 0.0 & 0.0 & 0.0 & 0.0 & 0.0 & 8.6 & 7.8 & 0.0 & 0.2 & 0.6 \\
\hline Switchboard & 0.0 & 0.0 & 0.0 & 0.0 & 0.0 & 13.5 & 13.4 & 0.0 & 0.0 & 0.1 \\
\hline Boiler & 9.3 & 0.5 & 3.1 & 0.0 & 0.2 & 0.0 & 0.0 & 0.0 & 0.0 & 5.9 \\
\hline Tank clearing & 0.0 & 0.0 & 0.0 & 1.4 & 0.3 & 0.0 & 0.0 & 0.0 & 0.3 & 0.9 \\
\hline Fuel heating & 0.0 & 0.0 & 0.0 & 3.2 & 0.5 & 0.0 & 0.0 & 0.0 & 0.7 & 2.0 \\
\hline Hotel facilities & 0.0 & 0.0 & 0.0 & 1.3 & 0.2 & 0.0 & 0.0 & 0.5 & 0.9 & 0.8 \\
\hline Auxiliary engines & 17.0 & 0.0 & 1.9 & 0.0 & 0.0 & 0.0 & 5.7 & 0.0 & 1.4 & 8.0 \\
\hline
\end{tabular}

\section{Discussion}

The implications of the hypotheses made in this study will be here further discussed, together with the generalizability of the results.

\subsection{Generalization of the Results}

The numerical results presented in the energy and exergy analysis are expected to be representative of the selected vessel and its sister ships: as aggregated data over one year of operation were used, any voyage-specific feature (weather influence on propulsive power, sea water temperature, etc.) is supposed to be levelled when accounting for longer periods of time.

It should be noted, however, that some phenomena can be observable only under longer time perspectives. In particular, today's low markets and high fuel prices have pushed down the operative speed of the vessel, and it is reasonable to expect that the share of propulsive power would be larger (together with recoverable energy) if the vessel were to operate at higher speed.

The variability of ship operational speed is the most important limit to the generalization of the results for future operations of the same vessel, as changes in market conditions could easily lead to an increase in the average operational speed. Were the engines to be operated at higher average load, it would be possible to see a number of changes, such as:

- Increase of propulsion share of total energy consumption

- Increase of the share of the HT stage in the heat balance of the CAC.

- Larger waste flows, both in exergy and energy terms.

The large influence of vessel speed on ship energy systems performance makes the design and retrofitting on these systems a challenge.

There are a number of conditions for the extension of the results presented in this study to other vessels.

The vessel should not present any major ship-specific auxiliary power or heat demand. In the case of chemical tankers, this reduces to the operations of tank cleaning and nitrogen compressors, which only account for a minor share of the total energy demand. Ships like passenger ships or reefers have a remarkably different energy demand and are therefore not represented by the vessel studied in this work.
The propulsion system of this ship is based on fourstroke engines. Although the difference in efficiency compared to two-stroke engines of similar size is limited, it could still be seen in the analysis. In addition, exhaust temperatures are significantly lower in the case of twostroke engines, making results related to the waste heat availability in the exhaust gas obtained in this study not applicable to two-stroke engine powered vessels.

Finally, the study presented in this paper does not account for dynamic ship behavior. This approximation is justified in the case of merchant, ocean going vessels, but not in the case of small ferries, tugs, or in general other ships were the dynamic component of the energy consumption cannot be neglected.

We therefore call for more case studies related to energy and exergy analysis of ship energy systems, particularly in relation to other vessel types. The extension of the results of this work to other ship categories would improve the understanding of ship energy systems and reinforce the need for the utilization of these methods in efforts for improving ship design, retrofitting, and operations.

\subsection{Input Data}

One strength of the procedure employed lies in the variety of input data that can be used in order to elaborate the structure of on board energy flows. Input data for calculations were obtained from the CMS, manufacturers' technical documentation, shipyard technical documentation, and reported measurements from the crew. This mixture of different data sources made it possible to use all available information, with the drawback of reduced consistency in data sources and accuracy.

Some variables were not measured and needed to be either assumed or calculated. This was particularly limiting in the case of exhaust gas and air properties (flow and temperature), which were calculated based on the regression of manufacturer's data. In reality many parameters, such as engine and turbocharger wear and fuel type, will influence engine performance.

Heat flows to jacket water and lubricating oil also had to be estimated based on the assumption that the engine behaves according to manufacturer's information.

Regressions also required extrapolation outside of the original domain whenever the engine load was measured to be below $50 \%$ of the engine MCR. Apart from air and 
exhaust temperatures, unfortunately, all other aforementioned variables are very seldom measured on board of existing vessels and it is therefore expectable that approximations will be required also for future similar studies. The estimation of heat was also based on a large number of assumptions and is should therefore be treated with care. The same can be said for the repartition of auxiliary power demand among individual consumers.

The availability of measurements of total heat demand, as well as of individual heat and power consumers, would provide the possibility to discuss savings related to consumers, and not only to converters. Heat demand for hotel facilities, for instance, is largely influenced by the assumptions employed in the calculation of the required amount of freshwater to be generated onboard, which is determined according to common practice and is therefore subject to large variability.

Given the absence of available measurements, it was not possible to validate the assumptions employed in this study.

\section{Conclusions}

The paper presented the energy and exergy analysis of a chemical / product tanker, based on a mixed top-down and bottom-up approach applied to one year of ship operation. The exergy analysis was used as a basis for evaluating the potential for waste heat recovery on the vessel.

The application of the proposed method to the case study ship led to an improved understanding of onboard energy use and of inefficiencies in the system, obtained through the estimation of energy and exergy flows. Energy analysis allows estimating the main consumers, producers, and hence allows understanding where most of the energy goes and were losses are located. Exergy analysis, on the other hand, improves the understanding of the potential for WHR, and helps in the identification of inefficiencies in the handling of waste heat.

The analysis showed, as expected, that propulsion power is the major energy consumption (68\%), while also demonstrating that auxiliary demands of both electric power $(12 \%)$ and heat $(20 \%)$ are not negligible. A large amount of energy is wasted to the environment through the engine cooling and the exhaust gas. Using exergy analysis, the potential for WHR from these losses was estimated. Large amounts of exergy are destroyed in the cooling systems, as exchanges are not optimized for conserving energy quality.

The availability of such amounts of waste heat would suggest further investigating the possibility of installing WHR systems; future work can be directed towards the design and optimization of WHR cycles for the generation of auxiliary power, such as steam-based and Organic Rankine cycles, which have been extensively treated in literature (e.g. Larsen et al. [28]). In addition to the aforementioned technologies, complementary uses for waste heat from Diesel engines for shipping application have been extensively reviewed by Shu et al. [30]

\section{Acknowledgments}

The work presented in this paper is part of a larger project entitled "energy systems modelling in shipping" financed by the Swedish Energy Agency and part of the Lighthouse competence center. The authors would also like to thank Laurin Maritime and all its employees for the supportive and collaborative attitude that made it possible to achieve the results of this work.

\section{Appendix A}

Table A1. Defining Equations and Assumptions for on Board Material Flows.

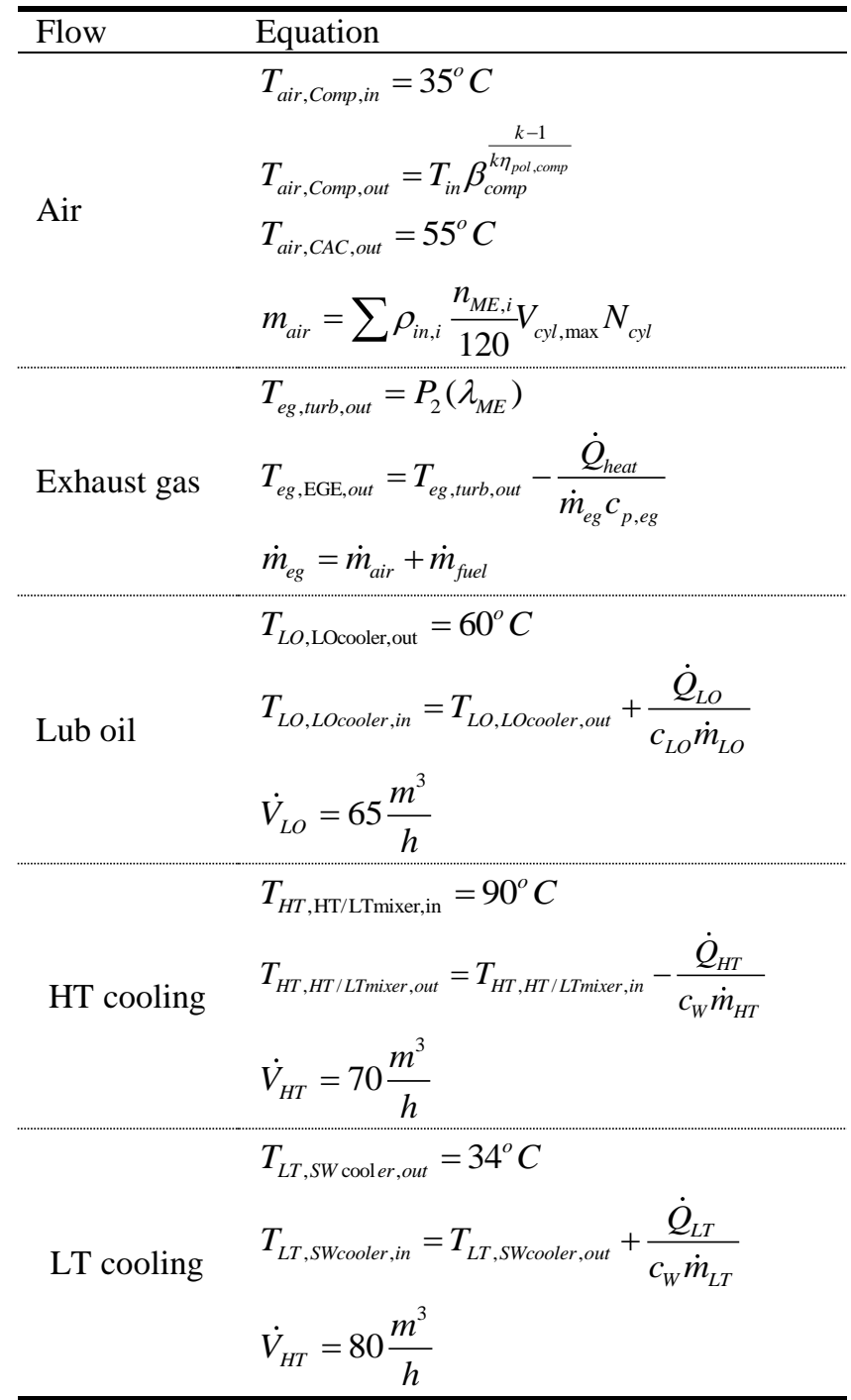

Table A2. Defining Equations and Assumptions for on Board Energy Flows.

\begin{tabular}{ll}
\hline Energy flow & Equation \\
\hline $\begin{array}{l}\text { Exhaust gas } \\
\text { Charge air }\end{array}$ & $\dot{Q}_{e g}=\dot{m}_{e g} c_{p, e g}\left(T_{e g, \text { turb,out }}-T_{0}\right)$ \\
cooler & $\dot{Q}_{C A C}=\dot{m}_{\text {air }} c_{p, \text { air }}\left(T_{\text {air, comp }, \text { out }}-T_{\text {air, comp }, \text { in }}\right)$ \\
Jacket water & $\dot{Q}_{J W}=0.414\left(\dot{Q}_{f u e l}-\dot{W}-\dot{Q}_{e g}-\dot{Q}_{C A C}\right)$ \\
cooling & $\dot{Q}_{L O}=0.444\left(\dot{Q}_{\text {fuel }}-\dot{W}-\dot{Q}_{e g}-\dot{Q}_{C A C}\right)$ \\
Lub oil cooling & $\dot{Q}_{H T}=\dot{Q}_{J W}+P_{2}\left(\lambda_{M E}\right) \dot{Q}_{C A C}$ \\
HT cooling & $\dot{Q}_{L T}=\dot{Q}_{L O}+\dot{Q}_{C A C}+\dot{Q}_{J W}-\dot{Q}_{F W g e n}$ \\
LT cooling & $\frac{P_{p r o p}}{\eta_{s h a f t}}+\frac{P_{S G}}{\eta_{S G}}$ \\
Main engine & $\eta_{G B}$ \\
power & $P_{M E}=\frac{P_{A G}}{\eta_{A G}}$ \\
$\begin{array}{l}\text { Auxiliary } \\
\text { engine power }\end{array}$ & $P_{A E}$ \\
\hline
\end{tabular}


Table A3. Defining Equations and Assumptions for Selected Components.

\begin{tabular}{ll}
\hline Component & Equation \\
\hline Compressor & $\beta_{\text {comp }}=P_{2}\left(\lambda_{M E}\right)$ \\
Compressor & $\eta_{p o l, c o m p}=P_{2}\left(\lambda_{M E}\right)$ \\
Shaft generator & $\eta_{S G}=0.95 P_{2 .}\left(\lambda_{S G}\right)[25]$ \\
Gearbox & $\eta_{G B}=0.983$ \\
Shaft & $\eta_{\text {shaft }}=0.99[12]$ \\
\hline
\end{tabular}

\section{Nomenclature}

$b \quad$ specific exergy, $\mathrm{J} / \mathrm{kg}$

$B \quad$ exergy, $\mathrm{J}$

$\dot{B} \quad$ exergy flow, W

bsfc break specific fuel consumption, $\mathrm{g} / \mathrm{kWh}$

c specific heat, $\mathrm{J} / \mathrm{kg} \mathrm{K}$

E energy, J

$\dot{E} \quad$ energy flow, W

$h \quad$ specific enthalpy, $\mathrm{J} / \mathrm{kg}$

i irreversibility rate, $\mathrm{W}$

$\mathrm{k} \quad$ specific heat ratio

m mass, $\mathrm{kg}$

$\dot{m} \quad$ mass flow, $\mathrm{kg} / \mathrm{s}$

$n \quad$ rotational speed, $\mathrm{rpm}$

$N_{c y l} \quad$ number of cylinders

$p \quad$ pressure

$P_{n} \quad$ polynomial of order $n$

$\dot{Q} \quad$ heat flow, W

$s \quad$ specific entropy, $\mathrm{J} /(\mathrm{kg} \mathrm{K})$

$\dot{S}_{g e n} \quad$ entropy generation rate, W/K

$T \quad$ Temperature, $\mathrm{K}$ or ${ }^{\circ} \mathrm{C}$

$V \quad$ Volume, $\mathrm{m}^{3}$

$\dot{V} \quad$ Volume flow, $\mathrm{m}^{3} / \mathrm{s}$

Acronymes

AE auxiliary engine

AG auxiliary generator

CAC charge air cooler

CMS continuous monitoring system

EGE exhaust gas economizer

HT high temperature

JW Jacket water

LO lubricating oil

LT low temperature

$\mathrm{ME} \quad$ main engine

SG shaft generator

SW sea water

WHR waste heat recovery

Greek letters

$\begin{array}{ll}\beta & \text { compression ratio } \\ \lambda & \text { engine load } \\ \delta & \text { irreversibility share } \\ \varepsilon_{t} & \text { total exergy efficiency } \\ \varepsilon_{u} & \text { task efficiency } \\ \gamma & \text { irreversibility ratio } \\ \eta & \text { energy efficiency } \\ \rho & \text { density, } \mathrm{kg} / \mathrm{m}^{3} \\ \Delta & \text { finite difference }\end{array}$

Subscripts

$\begin{array}{ll}c & \text { cold } \\ \text { comp } & \text { compressor } \\ \text { eg } & \text { exhaust gas } \\ h & \text { hot } \\ i & \text { component } \\ \text { in } & \text { inlet flow } \\ \text { out } & \text { output flow } \\ p & \text { paid } \\ \text { pol } & \text { politropic } \\ \text { prop } & \text { propeller } \\ \text { tot } & \text { total } \\ u & \text { useful } \\ 0 & \text { reference state }\end{array}$

\section{References:}

[1] WTO, "International Trade Statistics," World Trade Organization, 2012.

[2] UNCTAD, "Review of maritime transport," United Conference on Trade and Development, 2012.

[3] IEA, "CO2 emissions from fuel combustion highlights," International Energy Agency OECD, Paris, France, 2012.

[4] J. Kalli, T. Karvonen, and T. Makkonen, "Sulphur content in ships bunker fuel in 2015 - A study on the impacts of the new IMO regulations and transportation costs," Ministry of Transport and Communications, Helsinki, Finland, 2009.

[5] T. W. P. Smith, J. P. Jalkanen, B. A. Anderson, J. J. Corbett, J. Faber, S. Hanayama, and E. Al., "Third IMO GHG Study," London, UK, 2014.

[6] DNV, "Shipping 2020," Det Norske Veritas, Oslo, Norway, 2012.

[7] DNV, "Pathways to low carbon shipping - Abatement potential towards 2020," Det Norske Veritas, Oslo, Norway, 2010.

[8] O. Buhaug, J. J. Corbett, O. Endersen, V. Eyring, J. Faber, S. Hanayama, D. S. Lee, H. Lindstad, A. Z. Markowska, A. Mjelde, J. Nilsen, C. Palsson, J. J. Winebrake, W. Wu, and K. Yoshida, "Second IMO GHG Study 2009," International Maritime Organization (IMO), London, UK, 2009.

[9] M. S. Eide, T. Longva, P. Hoffmann, Ø. Endresen, and S. B. Dalsøren, "Future cost scenarios for reduction of ship CO2emissions," Marit. Policy Manag., vol. 38, no. 1, pp. 11-37, 2011.

[10]O. C. Basurko, G. Gabiña, and Z. Uriondo, "Energy performance of fishing vessels and potential savings," $J$. Clean. Prod., vol. 54, pp. 30-40, 2013.

[11] W. Shi, H. T. Grimmelius, and D. Stapersma, "Analysis of ship propulsion system behaviour and the impact on fuel consumption," Int. Shipbuild. Prog., vol. 57, no. 12, pp. 35-64, 2010.

[12] W. Shi, D. Stapersma, and H. T. Grimmelius, “Analysis of energy conversion in ship propulsion system in offdesign operation conditions," WIT Trans. Econogy Environ., vol. 121, pp. 461-472, 2009. 
[13] R. Balaji and O. Yaakob, "An analysis of shipboard waste heat availability for ballast water treatment," Proc. Inst. Mar. Eng. Sci. Technol. Part A J. Mar. Eng. Technol., vol. 11, no. 2, pp. 15-29, 2012.

[14] T.-V. Nguyen, L. Pierobon, B. Elmegaard, F. Haglind, P. Breuhaus, and M. Voldsund, "Exergetic assessment of energy systems on North Sea oil and gas platforms," Energy, vol. 62, pp. 23-36, 2013.

[15] Z. Zaili and Y. Zhaofeng, "Exergy analysis of ship main propulsion plant integrated energy system," Proceedings of the International Conference on Technology Management and Innovation. Wuhan, China, 2010

[16] T. J. Kotas, The Exergy Method of Thermal Plant Analysis. Krieger Publishing, 1995.

[17] B. C. Choi and Y. M. Kim, "Exhaust-gas heatrecovery system of marine diesel engine (II) Exergy analysis for working fluids of R245fa and water," Trans. Korean Soc. Mech. Eng. B, vol. 36, no. 6, pp. 593-600, 2012.

[18] G. G. Dimopoulos, C. A. Georgopoulou, and N. M. P. Kakalis, "The introduction of exergy analysis to the thermo-economic modelling and optimisation of a marine combined cycle system," ECOS, 2012.

[19] R. Y. Lin, X. Yu, J. Li, Y. Li, and W. Wang, "Exergy analysis for LNG refrigeration cycle," in International Conference on Computer Distributed Control and Intelligent Environmental Monitoring (CDCIEM), pp. 211-214, 2011

[20] L. Mattarolo, "Energy economy and heat recovery with particular reference to sea transport," Int. J. Refrig., vol. 9, no. 1, pp. 6-12, 1986.

[21] J. Szargut, D. R. Morris, and F. R. Steward, Exergy Analysis of Thermal, Chemical, and Metallurgical Processes. Hemisphere, 1988.

[22] N. Lior and N. Zhang, "Energy, exergy, and Second Law performance criteria," Energy, vol. 32, no. 4, pp. 281-296, 2007.
[23] E. A. Bruges, "Performance of heat exchangers," Eng., vol. 204, p. 225, 1957.

[24] T. Kotas, "Exergy criteria of performance for thermal plant: second of two papers on exergy techniques in thermodynamic plant analysis," Int. $J$. Heat Fluid Flow, vol. 2, pp. 147-163, 1980.

[25] W. L. McCarthy, W. S. Peters, and D. R. Rodger, "Marine Diesel power plant practices," Jersey City, US, 1990.

[26] G. G. Dimopoulos, C. A. Georgopoulou, and N. M. P. Kakalis, "Modelling and optimization of an integrated marine combined cycle system," in Proceedings of the International Conference on Efficiency, Cost, Optimization, Simulation and Environmental Impact of Energy Systems (ECOS), 2011.

[27] G. Theotokatos and G. A. Livanos, "Technoeconomical analysis of single pressure exhaust gas waste heat recovery systems in marine propulsion plants," Proc. Inst. Mech. Eng. Part M J. Eng. Marit. Environ., vol. 227, no. 2, pp. 83-97, 2012.

[28] U. Larsen, L. Pierobon, F. Haglind, and C. Gabrielii, "Design and optimisation of organic Rankine cycles for waste heat recovery in marine applications using the principles of natural selection," Energy, vol. 55, pp. 803-812, 2013.

[29] J. Szargut and D. Sama, "Practical rules of the reduction of exergy losses caused by the thermodynamic imperfection of thermal processes," in Second International Thermal Energy Conference, 1995, pp. 782-785.

[30] G. Shu, Y. Liang, H. Wei, H. Tian, J. Zhao, and L. Liu, "A review of waste heat recovery on twostroke IC engine aboard ships," Renew. Sustain. Energy Rev., vol. 19, pp. 385-401, 2013. 